Journal of Molecular Docking

Vol 1 Issue 2 December 2021

Pages $68-77$

Original Research Article

\title{
New Approach to create an Effective Natural Treatments of Infections caused by Human Papillomavirus
}

\section{Momir Dunjic 1,2,3,4 \\ Stefano Giuseppe Turini $3,4,5^{*}$ \\ Slavisa Stanisic 1,2,3 \\ Nenad Sulovic 1 (b) \\ Sasa Cvetkovic 1 \\ Dejan Mihajlovic ${ }^{1}$ \\ Marija Dunjic 6 \\ Dusan Simic 7 \\ Katarina Dunjic 4 \\ 1School of Medicine, Univerzitet $\mathrm{u}$ Prištini, Kosovska Mitrovica, Serbia \\ 2Faculty of Pharmacy, Univerzitet Privredna Akademija u Novom Sadu, Novi Sad, Serbia \\ ${ }^{3}$ Alma Mater Europaea - ECM, Maribor, Slovenia \\ 4BDORT Center for Functional Supplementation and Integrative Medicine, Belgrade, Serbia \\ 5Unique Treatments Doo, Belgrade, Serbia \\ ${ }^{6}$ Department of Plastic and Reconstructive Surgery, Military Medical Academy, Univerzitet Odbrane. Belgrade, Serbia \\ 7Department of Obstetrics and Gynecology, Vojvode Tankosica Health Center, Niš, Serbia \\ *email: turini.stefano@yahoo.it}

\section{Keywords:}

1-Click Docking

Apigenin

Celery

Cervical carcinoma

HPV-16

Major capsid protein L1

\begin{abstract}
Human Papillomavirus (HPV) has a double-stranded DNA (dsDNA) genome. Infections, mainly sexually transmitted, usually resolve spontaneously. However, if the infection persists over time, lesions of the skin and mucous membranes tend to appear, notably mucosal lesions in the cervix or the appearance of warts. Some of those slowly progress to cancers such as cervical, oral, anus, esophagus, and larynx carcinoma. Diagnosis of an HPV infection is made by Papanicolaou test (Pap test) or molecular screening such as the HPV DNA Test. Treatment with natural products is based on essential oils. The main point of this work is to identify natural molecules from vegetal derivation capable of inhibiting the proliferation of HPV-16 with the same and/or superior affinity as regular drugs used in pharmacological treatment. Once we have identified the main components in these plants, we have applied molecular docking software 1-Click Docking, for virtual testing of those, on main antigenic determinants of HPV-16 as oncoproteins E6 and E7 as well as major capsid protein L1. The major active component to bind oncoprotein E6, apigenin, has shown an affinity bigger than other molecules. For major capsid protein L1, apigenin has shown one level of affinity similar to conventional drugs. These results have shown how it is possible, with natural products present in our daily lives, to inhibit the proliferation of HPV.
\end{abstract}

Received: December $4^{\text {th }}, 2021$

Accepted: December 20th, 2021

Published: December 30th, 2021 


\section{INTRODUCTION}

Human papillomavirus (HPV) is a non-enveloped viral particle, i.e., not equipped with a pericapsid, belonging to the Papillomaviridae family and with an icosahedral symmetrical capsid whose diameter is about $50 \mathrm{~nm}$. It comprises 72 capsomers which can be both pentamers and hexamers (usually 60 hexamers and 12 pentamers are found). Inside the protective capsid, there is a genome consisting of double-strand of DNA (dsDNA), about $8 \mathrm{~kb}$ long, which has six early genes, coding for proteins E1 to E7 (therefore also the E6 oncoprotein), not including E3, and two late genes, encoding proteins L1 or major capsid protein and L2 or minor capsid protein 1 . Upstream early genes are a regulatory region containing the seat/origin of replication, some transcription regulating sequences, and an N-terminal sequence typical to all early proteins ${ }^{2}$. The early proteins' purpose/function is to modify the metabolism of an infected cell so it can support by HPV, while the late ones are structural proteins, which, by associating with each other, form an icosahedral structure of a viral capsid ${ }^{3}$.

About $90 \%$ of papillomavirus infections are asymptomatic and resolve spontaneously within approximately two years. In some cases, infections persist, resulting in the appearance of mucosal and skin lesions colloquially called warts, common to HPV-6 and HPV-11 strains, and pre-cancerous conditions. Depending on the anatomical portion or the tissue involved, these pre-cancerous lesions can give rise to cancer in the cervix, vulva, vagina, penis, anus, mouth, and throat ${ }^{4,5}$.

The oncogenic strains are predominantly HPV-16 and HPV-18, with high oncogenic risks. However, among the oncogenic strains, referring to cancers of the genital areas, there are also HPV-31 and HPV-45 strains, representing high oncogenic risk factors. Then there are "other high risk" strains, such as HPV-33, 35, 39, 51, 52, 56, 58, 59 and some "probable high risk" strains such as HPV-26, 53, 66, 68, 73, 826,7. Typically, papillomavirus infections are diagnosed using the well-known Papanicolaou test (Pap test), a cervical screening method capable of identifying potential precancerous and cancerous processes in the cervix or colon (depending on the patients' gender) . $^{8}$

Apart from screening tests, the introduction of vaccination into many countries has made it possible to provide a highly effective prevention model against infections and cancerous lesions caused by HPV. The two forms of the vaccine on the market are known under the following trade names: cervarix and gardasil ${ }^{9}$. The first is a divalent form of the vaccine, consisting of protein subunits of the HPV-16 and HPV18 strains. The second is a type of quadrivalentrecombinant vaccine, which comprises the protein subunits of HPV-6, 11, 16, and 18 strains $^{10}$.

To date, 170 different serotypes/strains of papillomavirus have been classified, 40 of which are transmitted sexually, through anal or genital contact. One of the features concerning HPV infections is that they can be transmitted from mother to fetus, therefore vertically, transplacental, and through the umbilical artery. It has not yet been identified if genital papillomavirus infections can be transmitted through infected surfaces (fomites), such as during contact with infected toilet ceramics. However, as far as warts are concerned, they are easily transmitted, especially through contact with infected floors, especially if made of wood ${ }^{11}$. A further prevention includes the use of disinfection products such as sodium hypochlorite $(\mathrm{NaClO})$, used in a diluted form, disinfection of the surfaces using UV rays, hydrogen peroxide $\left(\mathrm{H}_{2} \mathrm{O}_{2}\right)$, and chlorine dioxide $\left(\mathrm{ClO}_{2}\right)$ solutions ${ }^{12,13}$.

The treatment of the clinical manifestations of papillomavirus infections differs depending on the type involved. Condylomas, for example, can be treated by thermal therapy, specifically cryoablation. For tumor forms deriving from oncogenic strains, a pharmacological treatment based on antineoplastic chemotherapy such as cisplatin and surgical interventions such as hysterectomy and radiotherapy is outlined ${ }^{14}$. Although there is no specific therapy in treating HPV infection, some medications can help contain the infection ${ }^{15}$. NYU Langone Health in New York City recommends some products for such infection: imiquimod, as topical medication helps eliminate warts by boosting the immune system. It is typically applied at home once a day, three times a week, for 16 weeks. Sexual contact should be avoided while using this medication because it can weaken condoms or vaginal diaphragms ${ }^{16}$. Podofilox stops the growth of cells that cause genital warts. It is applied to warts at home with a cotton swab twice a day for three days, followed by a rest period of four days. This can be repeated for up to four treatment cycles until warts go away. Because genital warts may still be contagious during treatment, sexual contact should be avoided 
while using this medication ${ }^{17}$. Sinecatechins, obtained from the extract of green tea leaves, are medications used to treat warts on the penis, the vulva, and the outside of the anus. The most common side effects are burning, itching, redness, pain, ulcers, swelling, and rash $^{18}$. Trichloroacetic acid is a medication that dissolves genital warts by destroying the proteins in their cells. It is typically used on small warts on the vulva, vagina, or anus. Because trichloroacetic acid can damage the skin around the wart, it is applied in the doctor's office. The treatment can be repeated weekly, as needed ${ }^{19}$. Alongside the pharmacological treatment or surgical resection, which has become a part of the conventional procedure, there is another option consisting of the treatment based on using natural products, i.e., extracts of vegetable origin and essential oils (in particular cold-pressed and etheric oils) ${ }^{20}$. Our previous study also concerned with applying an integrated approach to HPV infections treatment ${ }^{21}$.

Thanks to research with advanced bioinformatics software such as molecular modeling and docking, it was possible to reconstruct virtual and threedimensional models of the main oncogenic proteins of the HPV-16 and 18 strains: oncoprotein E622,23, and to determine in which region of the molecule in question there is a high degree of affinity (measured in $\mathrm{kcal} / \mathrm{mol}$ ), between the oncoprotein E6 and the most representative molecular determinant present within the essential oil. Molecular docking consists of a virtual molecular modeling technique, which makes it possible to establish in which site of a target molecule (in this case, a protein) it could bind (speaking from a statistical point of view) and with which space-time configuration, a specific ligand ${ }^{24}$. The bond strength, measured in $\mathrm{kcal} / \mathrm{mol}$, determines the affinity of a ligand for its target; the higher the affinity, the greater the bond strength. The key to interpreting molecular docking lies in thermodynamics and the concept of exergonic and endergonic reactions. If the affinity between a ligand and its target is high, the reaction will occur spontaneously, releasing energy into the environment. In this case, it is said that the reaction is exergonic, and the numerical coefficient defining it will be preceded by a negative sign ${ }^{25}$ (for example, $9.45 \mathrm{kcal} / \mathrm{mol})$.

If the affinity between a ligand and a target molecule is low, then their bonding will occur in a nonspontaneous way, and it will be necessary to provide energy for the bond to occur. In this case, a reaction taking place in response to the need for energy supply is necessary to supply energy, is defined as endergonic, and its numerical coefficient will be preceded by a positive sign $^{26}$ (for example, +9.45 $\mathrm{kcal} / \mathrm{mol})$. Obviously, speaking of the relationship between molecular affinity and binding energy, the more negative the numerical value, the greater the affinity. For example, the bond energy value -9.45 $\mathrm{kcal} / \mathrm{mol}$ implies a lower affinity than the value of $10.45 \mathrm{kcal} / \mathrm{mol}$. The software used for these studies was 1-Click Docking, produced by Mcule (https://mcule.com/apps/1-click-docking/).

In order to determine the nature and quality of the bond between ligand and target molecule, a series of experiments were performed, determining the bond energy values and plotting them in software, created on the spot, using an algorithm written in the Java platform (https://www.java.com/it/). Based on the value entered, it is possible to recognize if the goodness of the bond was classifiable as positive, positive-fair, positive-strong, and strong. After entering the numerical reference parameters for positive and positive-discrete bonds, the software returned a positive-strong or strong value based on the entered value higher than that of the aforementioned parameters ${ }^{27}$.

The basic structure in the flow chart of the algorithm, as mentioned earlier, is shown in Figure 1. The latter, unlike SwissDock, allows you to directly draw adhock molecules and add or remove chemical substituents or covalent bonds. This program, 1-ClickDocking, is also used for the virtual design of drugs and related bioinformatics and statistical analyzes before proceeding with the actual synthesis and subsequent phases of in vitro, pre-clinical and clinical experimentation. The results provided by the experimentation as mentioned earlier conducted by our group made it possible to identify which molecular determinants, present in the cold-pressed and etheric oils, are particularly effective in binding, with more or less high binding affinity, the oncoprotein E6 of the HPV (oncogenic strain HPV-16 that we had chosen as the target of our study). This allows us to understand better if the natural molecules are effective against HPV and can significantly reduce the side effects of conventional drug therapy. One of the aims of this study is to shed more light on oils therapy as supportive or integrated therapy and become a form of primary therapy. 


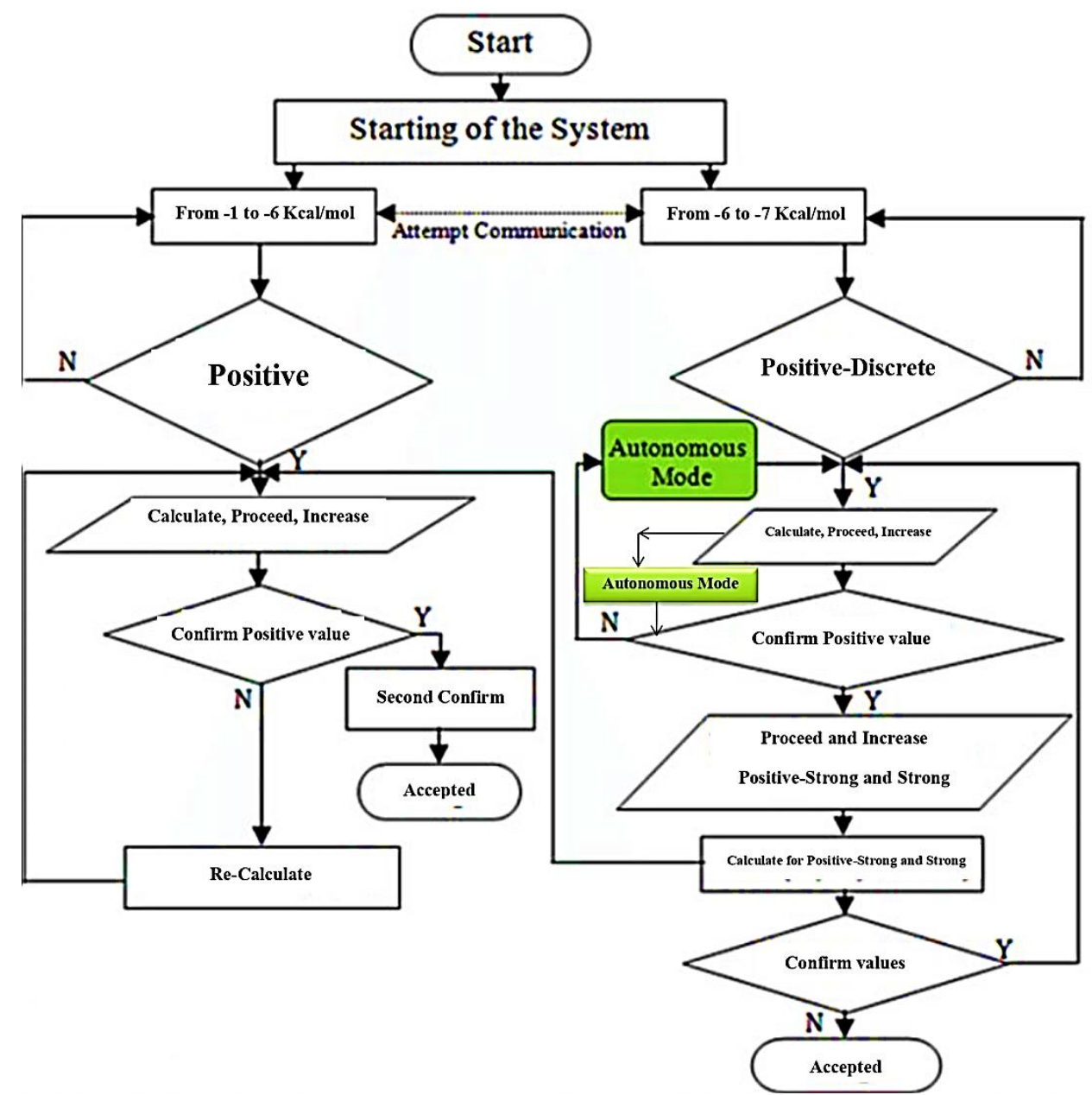

Figure 1. Flow chart of algorithm for bond's strength comparation with reference values.

\section{METHOD}

\section{Hardware and Software}

The hardware used was Asus Vivo PB62-B7017MH mini PC with Intel Core ${ }^{\mathrm{TM}} \mathrm{i} 7-117008 \times 2.50 \mathrm{GHz}$, Intel ${ }^{\circledR}$ UHD Graphics 750 Shared Memory, 16 GB RAM, 512 GB SSD, Wi-Fi 6 (802.11ax), 1x USB 3.1 Gen1 Typ C, 4x USB 3.1 Gen2, 1x USB 3.1 Gen1, 2x USB 2.0.

\section{Ligands}

The study focused on four kinds of mixed oils or oils made by a blend of essential oils, effective for HPV. We have detected these oils by using resonance phenomena of quantum medicine and then confirmed by molecular modelling software as 1-Click Docking. Furthermore, these four oils were divided into two types: cold-pressed and etheric oil. For each of the following components, the percent of each component/molecule was determined by searching the publications in which the information about their chemical composition and the molecules present with the highest percentage could be found. The five ligands were 2-acetylpyrrole (PubChem CID 14079), apigenin (5280443), ricinine (10666), oleic acid (445639), and curzerene (572766), which were described in detail in Table I. For the five ligands, four drug compounds that have been used to treat HPV infection were also used. The four compounds were imiquimod (57469), podofilox (10607), sinecatechins (46506183), and trichloroacetic acid (6421). The results of the docking of the five test ligands were compared with the comparison compounds to determine the potential of each test ligand.

Table I. Main chemical constituents of oils used for HPV infections prevention and treatment

\begin{tabular}{|c|c|c|c|}
\hline $\begin{array}{c}\text { Type of } \\
\text { oil }\end{array}$ & $\begin{array}{c}\text { Scientific } \\
\text { name }\end{array}$ & $\begin{array}{l}\text { Mode of } \\
\text { production }\end{array}$ & $\begin{array}{c}\text { Main } \\
\text { molecule }\end{array}$ \\
\hline $\begin{array}{l}\text { Cacao } \\
\text { oil }\end{array}$ & $\begin{array}{l}\text { Theobroma } \\
\text { cacao }\end{array}$ & $\begin{array}{l}\text { Cold- } \\
\text { pressed oil }\end{array}$ & 2-acetylpyrrole \\
\hline $\begin{array}{l}\text { Celery } \\
\text { oil }\end{array}$ & $\begin{array}{l}\text { Apium } \\
\text { graveolens }\end{array}$ & $\begin{array}{l}\text { Cold- } \\
\text { pressed oil }\end{array}$ & Apigenin \\
\hline $\begin{array}{l}\text { Ricinus } \\
\text { oil }\end{array}$ & $\begin{array}{l}\text { Ricinus } \\
\text { communis }\end{array}$ & $\begin{array}{l}\text { Cold- } \\
\text { pressed oil }\end{array}$ & Ricinine \\
\hline $\begin{array}{l}\text { Apricot } \\
\text { seed oil }\end{array}$ & $\begin{array}{l}\text { Prunus } \\
\text { armeniaca }\end{array}$ & $\begin{array}{l}\text { Cold- } \\
\text { pressed oil }\end{array}$ & Oleic acid \\
\hline $\begin{array}{l}\text { Myrrha } \\
\text { oil }\end{array}$ & $\begin{array}{l}\text { Commiphora } \\
\text { myrrha }\end{array}$ & Etheric oil & Curzerene \\
\hline
\end{tabular}




\section{Receptors}

The software Clustal Omega (https://www.ebi.ac.uk/Tools/msa/clustalo/) has been used for the primary sequences of the oncoproteins E6 and major capsid protein L1 belonging to the HPV-16-18-31-45 strains (those running the highest oncogenic risk). A fine cladogram/phylogram indicating a phylogenetical distance was obtained, indicating that the phylogenetic distance, reported here in terms of oncoprotein E6 primary sequence, is the same for the HPV-16 and 18 strains (0.0902778), as well as for the HPV-31 and 45 strains (0.171141) (Figure 2). It seems as if there was no phylogenetic distance between the sequences and, in the specific case of the present study, it is irrelevant to use the structure of the oncoprotein E6 of the HPV-16 and 18 strain. Despite their high oncogenic potential, strains HPV-31 and 45 were not considered for the following study. About major capsid protein L1, we have performed the exact protein alignment, using the same software for the same strains of HPV, i.e., HPV-16, 18, 31, 45. The results we have obtained possibly overlap with what we have previously obtained with oncoprotein E6. Since that sequences have the same profile (codestrain), in which HPV-16 was possible to overlap with HPV-31 (0.000990099) and HPV-18 was possible to overlap with HPV-45 (0.0606061); therefore, we use only the HPV-16 sequence as a representative one. In conclusion, the structure of major capsid protein L1 of HPV-16 was the same as HPV-31, as HPV-18 was the same as HPV-45. The structure of the two proteins used was presented in Figure 3.

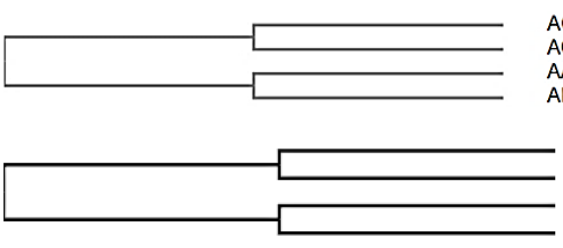

\section{AGG40787.1 0.0902778 QY61420.1 0.0902778 AAD33252.1 0.171141 \\ 160.000990099 310.000990099 180.0606061 450.0606061}

Figure 2. Cladogram/phylogram from protein alignment between oncoprotein E6 typical of four strains of HPV $(16,18$, 31, 45) with comparative code-strain AGG40787.1 (HPV-16), AQY61420.1 (HPV-18), AAD33252.1 (HPV-31), ABQ44348.1 (HPV-45) (top) and between major capsid protein L1 of four strains of $\operatorname{HPV}(16,18,31,45)$ (bottom).

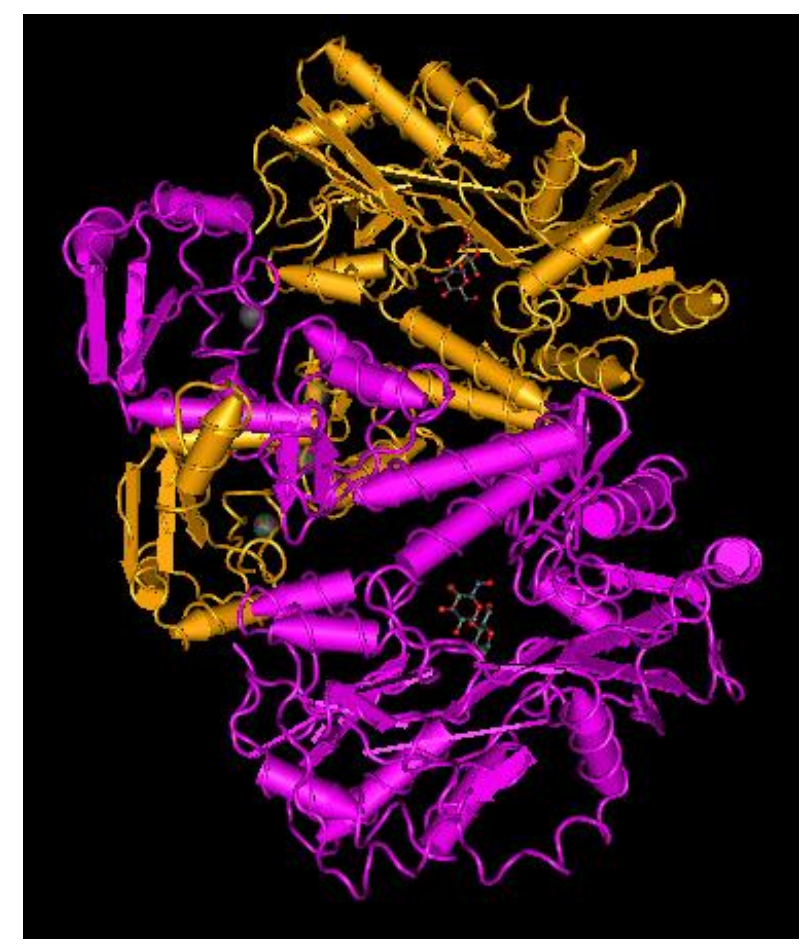

a

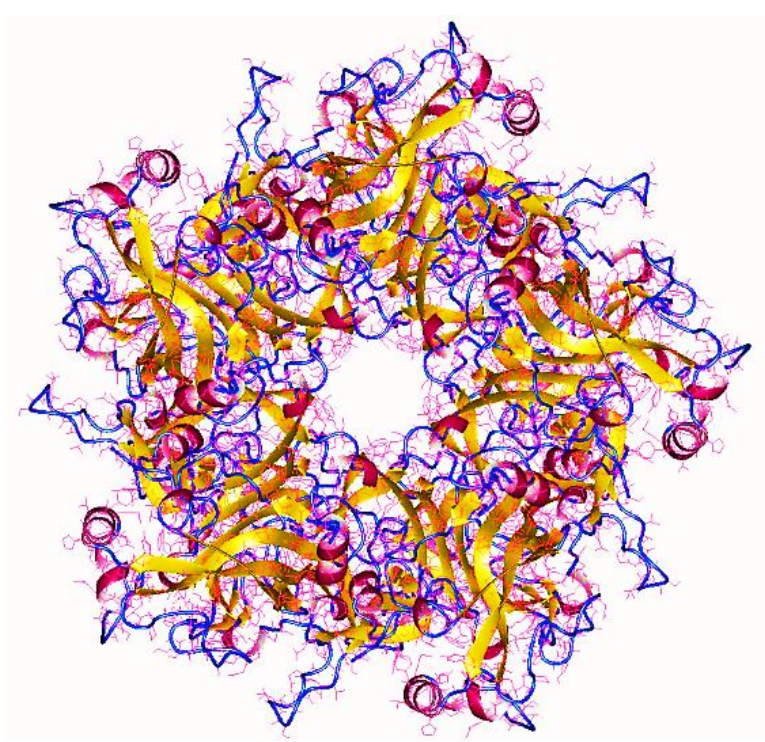

b

Figure 3. Structural-functional morphoanatomy topography of oncoprotein E6 (a) and major capsid protein L1 (b) of strain HPV-16.

\section{RESULTS AND DISCUSSION}

The data obtained through 1-Click-Docking led to the results shown in Table II. In order to interpret the results, it is advisable to compare them with a table chosen as a reference and containing the affinity values expressed in $\mathrm{kcal} / \mathrm{mol}$, according to the type and quality of the affinity itself ${ }^{28}$. Table III containing reference values was created after conducting a 
thorough search of relevant publications to interpret the data collected during molecular docking. The first finding was that all molecular docking values had a negative coefficient, which means that the binding between each ligand and the target molecules, in this case, the oncoprotein E6 and major capsid protein L1 of the HPV-16 strain, was spontaneous and also accompanied with a release of energy in the external reaction environment ${ }^{29}$. From the point of view of thermodynamics is said that reaction is exergonic ${ }^{30}$. Apigenin has positive-strong binding energy or affinity for both targets (Figures 4 and 5).
Results of affinity of oil's components are always considered compared with the affinity of conventional drugs used in treatments of HPV infections as imiquimod, podofilox, sinecatechins, and trichloroacetic acid. For oncoprotein E6, none of the conventional drugs have a strong bond affinity as apigenin, which remains the most effective agent. For major capsid protein L1, apigenin is comparable with podofilox and sinecatechins. It is closely followed by curzerene, the second most effective molecule for binding oncoprotein E6.

Table II. Results of molecular docking between ligands and receptors and amino acid residues involved in bonds

\begin{tabular}{llcc}
\hline \multicolumn{1}{c}{ Ligand } & \multicolumn{1}{c}{ Target (HPV-16) } & Affinity (kcal/mol) & Amino acid residues \\
\hline 2-acetylpyrrole & Oncoprotein E6 & -4.4 & Ile 23, Ile 24, Ala 28, Ile 47, Gly 48, Gly 49 \\
& Major capsid protein L1 & -2.6 & His 56, Asp 125, Gly 130, Gly 134 \\
Apigenin & Oncoprotein E6 & -7.8 & Gly 27, Ala 28, Gly 49, Pro 81, Val 82 \\
& Major capsid protein L1 & -3.7 & Asp 125, Gly 127, Gly 130, Phe 257 \\
Ricinine & Oncoprotein E6 & -4.8 & Leu 23, Gly 27 \\
& Major capsid protein L1 & -2.7 & Tyr 123, Pro 236, Phe 257, Asn 259 \\
Oleic acid & Oncoprotein E6 & -4.1 & Gly 48, Gly 51, Ile 53, Phe 53, Ile 54, Pro 81 \\
& Major capsid protein L1 & -1.9 & Asp 120, Gly 130, Gly 231, Phe 257 \\
Curzerene & Oncoprotein E6 & -6.2 & Leu 22, Asp 26, Gly 27, Ala 28 \\
\multirow{2}{*}{ Imiquimod } & Major capsid protein L1 & -3.0 & Asp 125, Gly 127, Asp 224, Val 226 \\
\multirow{4}{*}{ Podofilox } & Oncoprotein E6 & -4.1 & Thr 86, Thr 87, Arg 124, Tyr 124 \\
\multirow{3}{*}{ Sinecatechins } & Major capsid protein L1 & -3.6 & Val 126, Ser 129, His 256, Phe 257 \\
\multirow{2}{*}{ Trichloroacetic acid } & Oncoprotein E6 & -4.5 & Thr 86, His 121, Tyr 127, Pro 221 \\
& Major capsid protein L1 & -3.8 & Val 126, Gly 127, Asn 128, Phe 257 \\
& Oncoprotein E6 & -4.5 & Thr 84, Thr 87, His 126, Val 183 \\
& Major capsid protein L1 & -3.8 & Gly 130, Asn 143, His 256, Phe 257 \\
& Oncoprotein E6 & -2.6 & Thr 87, Tyr 124, Arg 124, Phe 125 \\
& Major capsid protein L1 & -2.4 & Tyr 123, His 256, Phe 257, Phe 258
\end{tabular}

Table III. Comparison of affinity to bond type

\begin{tabular}{cc}
\hline Affinity (kcal/mol) & Type/quality of affinity / bond \\
\hline-1 to -6 & Positive \\
-6 to -7 & Positive - Discrete \\
-7 to -8 & Positive - Strong \\
-8 to -9 & Strong \\
\hline
\end{tabular}

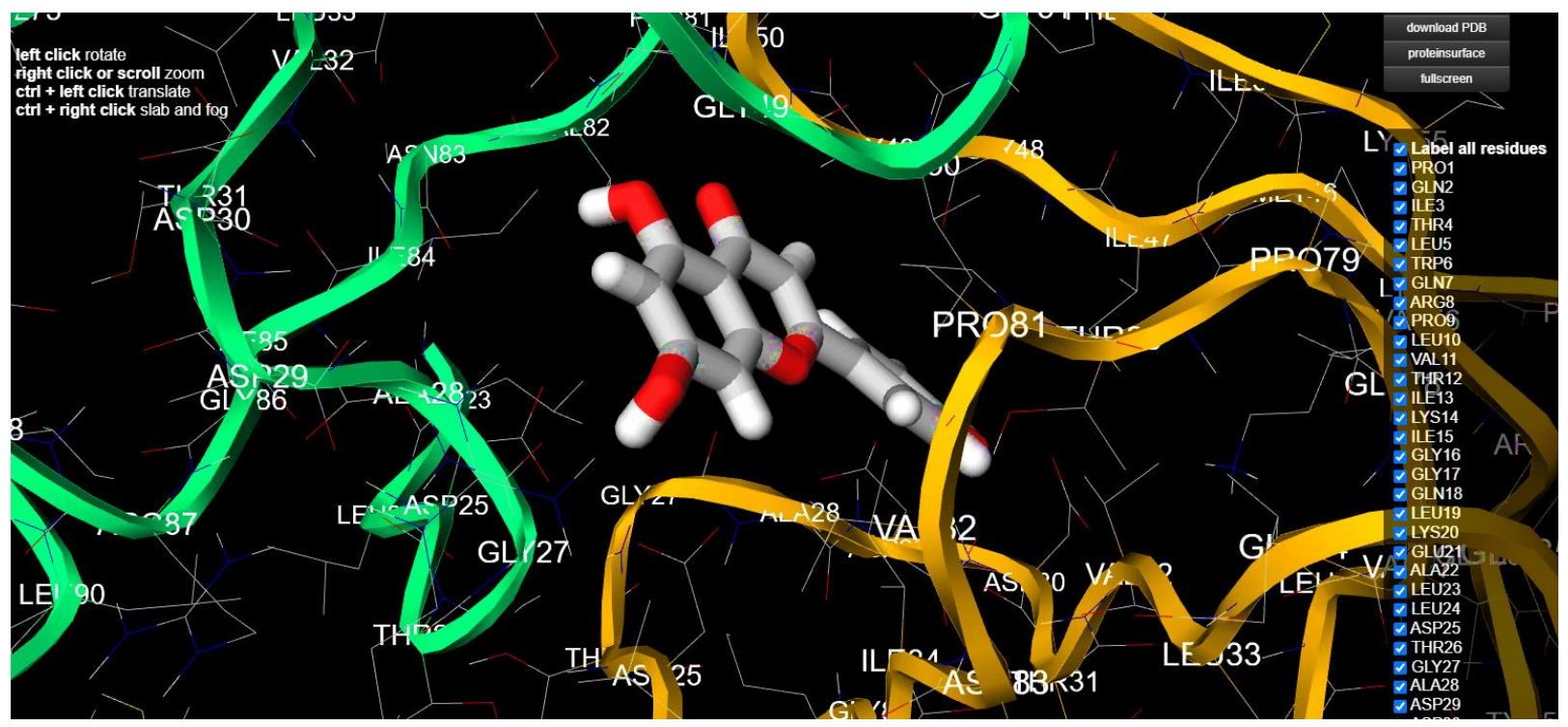

Figure 4. 3D elaboration of apigenin docking results on binding site oncoprotein E6. 


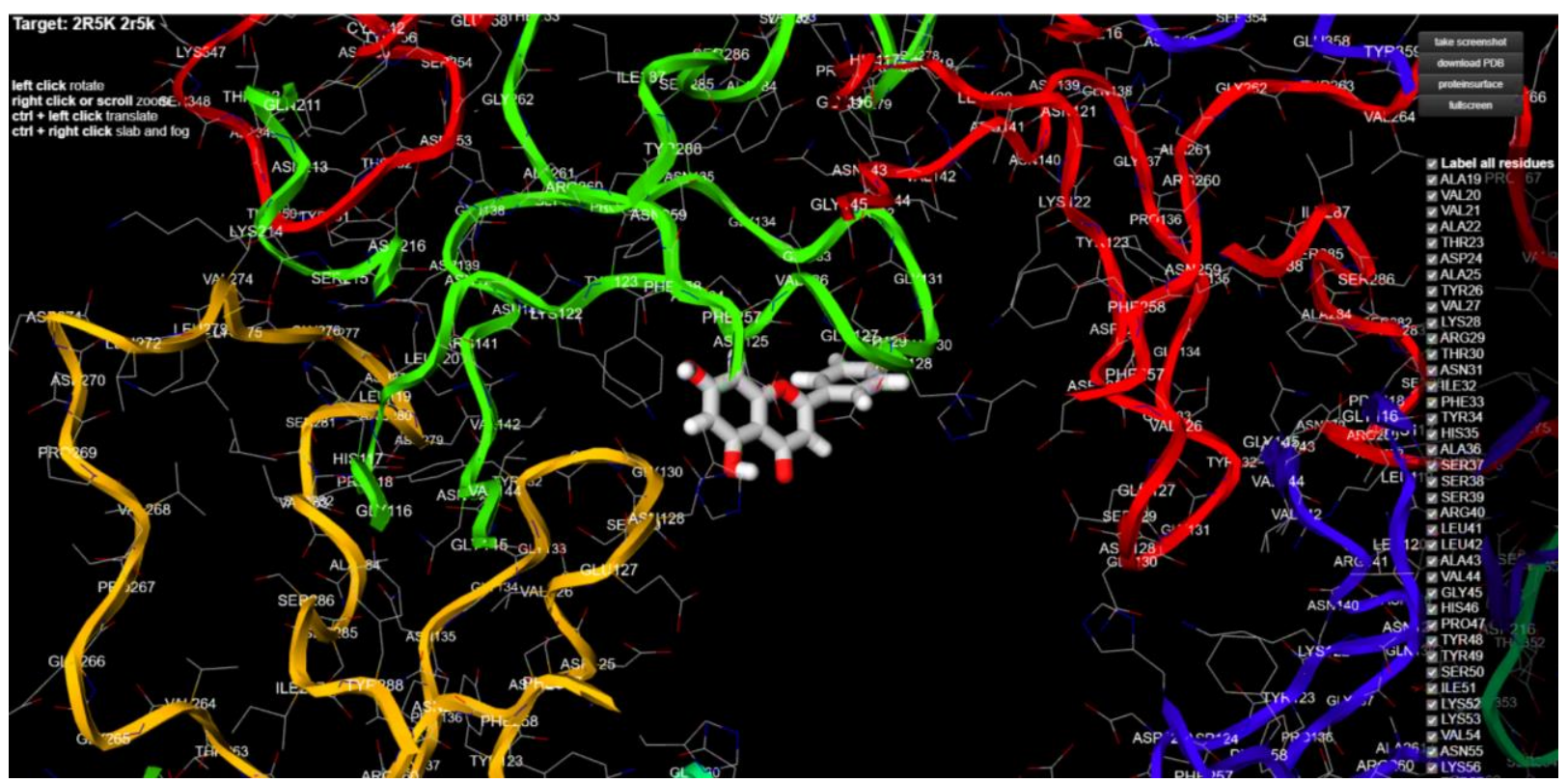

Figure 5. 3D elaboration of apigenin docking results on binding site major capsid protein L1.

As stated at the outset of this paper, each ligand examined by molecular docking appears to be capable of spontaneous interaction, while two particular ligands (apigenin and curzerene) showed a greater affinity than the others. In particular, apigenin has shown a particular affinity for binding both oncoprotein E6 and major capsid protein L1 of HPV16, compared with conventional drugs used as imiquimod, podofilox, sinecatechins, and trichloroacetic acid. Furthermore, a possible correlation between the affinity value and the number of amino acid residues involved in the bond did not prove to yield a significant result. Since using the logical deduction method according to which an affinity value is more significant if more amino acid residues are involved, the presence of a correlation could not be identified, at least as far as this typology of compounds is concerned ${ }^{31}$.

Apigenin features five amino acid residues most involved in binding with the target, thus being the molecule that has shown the most significant binding affinity. In the same way, oleic acid, while possessing the lowest binding energy value, has no less than six amino acid residues involved. A possible hypothesis as to why apigenin has the highest affinity value is that, among all the ligands, it is the most polar one, as it has 3-OH (hydroxyl) groups and an oxygen atom linked with a double bond interacting with the $-\mathrm{NH}_{3}$ (amine) and - $\mathrm{COOH}$ (carboxylic) amino acid residues groups $^{32}$. Thus, we can reasonably hypothesize the preparation of a subsequent type of oil-based solely on the combination of Apium graveolens and Commiphora myrrha shortly.

Furthermore, combining a cold-pressed oil with an etheric oil would also appear logical, whose functions are specific. While cold-pressed oil constitutes the base or the carrier for the transport of a specific component, etheric oil constitutes a catalyst allowing a successful reaction $^{33}$. For this reason, the choice between coldpressed and etheric oil must be specific and determined, as well as the proportions between the components themselves.

\section{CONCLUSION}

The study has been able to select two chemical compounds; those have shown a greater affinity for the targets (oncoprotein E6 and major capsid protein L1 of HPV-16 strain) as apigenin and curzerene, which could be taken into consideration for the preparation of additional oil for oral use or local applications and vaginal tablets. The theoretical work reported here aims to develop the aforementioned products in order to start a clinical trial to evaluate their effectiveness.

\section{CONFLICTS OF INTEREST}

The authors have no conflicts of interest to declare that are relevant to the content of this article. 


\section{FUNDING}

The work reported here did not require the procurement of specific funds as it was performed with software available online and without the aid of instruments, reagents, and equipment that required drawing on specific funding sources.

\section{DATA AVAILABILITY}

All data are available in the main text.

\section{ACKNOWLEDGMENTS}

The authors would like to thank the members of the BDORT Office specially, Center for Functional Supplementation and Integrative Medicine, located in Belgrade, Serbia, for their valuable contribution and support to the writing of this work, despite not appearing in work itself.

\section{AUTHORS' CONTRIBUTIONS}

Momir Dunjic: conceptualization, funding acquisition, investigation, methodology, project administration, resources, supervision, visualization. Stefano Giuseppe Turini: conceptualization, data curation, formal analysis, investigation, methodology, project administration, software, supervision, validation, visualization, writing - original draft, and writing - review \& editing. Slavisa Stanisic: conceptualization, investigation, methodology, validation, visualization, writing - review \& editing. Nenad Sulovic: conceptualization, investigation, methodology, validation, visualization, writing review \& editing. Sasa Cvetkovic: conceptualization, investigation, methodology, validation, visualization, writing - review \& editing. Dejan Mihajlovic: conceptualization, investigation, methodology, validation, visualization, writing - review \& editing. Marija Dunjic: conceptualization, investigation, methodology, validation, visualization, writing review \& editing. Dusan Simic: conceptualization, investigation, methodology, validation, visualization, writing - review \& editing. Katarina Dunjic: conceptualization, investigation, methodology, validation, visualization, writing - review \& editing.

\section{REFERENCES}

1. Conway MJ, Meyers C. Replication and assembly of human papillomaviruses. J Dent Res. 2009;88(4):307-17. doi:10.1177/0022034509333446

2. Yoshino M, Nagamatsu A, Tsutsumi K, Kanazawa A. The regulatory function of the upstream sequence of the beta-conglycinin alpha subunit gene in seed-specific transcription is associated with the presence of the RY sequence. Genes Genet Syst. 2006;81(2):135-41. doi:10.1266/ggs.81.135

3. Ferreira AR, Ramalho AC, Marques M, Ribeiro D. The Interplay between Antiviral Signalling and Carcinogenesis in Human Papillomavirus Infections. Cancers. 2020;12(3):646. doi:10.3390/cancers12030646

4. Ibarra AMR, Legendre L, Munday JS. Malignant Transformation of a Canine Papillomavirus Type 1-Induced Persistent Oral Papilloma in a 3-YearOld Dog. J Vet Dent. 2018;35(2):79-95. doi:10.1177/0898756418774575

5. Mirkovic J, Howitt BE, Roncarati P, Demoulin S, Suarez-Carmona M, Hubert P. Carcinogenic HPV infection in the cervical squamo-columnar junction. J Pathol. 2015;236(6):265-71. doi:10.1002/path.4533

6. Crosbie EJ, Einstein MH, Franceschi S, Kitchener HC. Human papillomavirus and cervical cancer. Lancet. 2013;382(9895):889-99. doi:10.1016/s01406736(13)60022-7

7. Gillison ML. Human papillomavirus-related diseases: oropharynx cancers and potential implications for adolescent HPV vaccination. J Adolesc Health. 2008;43(4 Suppl):S52-S60. doi:10.1016/j.jadohealth.2008.07.002

8. Koliopoulos G, Nyaga VN, Santesso N, Bryant A, Martin-Hirsch PP, Mustafa RA, et al. Cytology versus HPV testing for cervical cancer screening in the general population. Cochrane Database Syst Rev. 2017;8(8):CD008587. doi:10.1002/14651858.cd008587.pub2

9. El-Zein M, Richardson L, Franco EL. Cervical cancer screening of HPV vaccinated populations: Cytology, molecular testing, both or none. J Clin Virol. 2016;Suppl 1(Suppl 1):S62-S68. doi:10.1016/j.jcv.2015.11.020 
10. Maine D, Hurlburt S, Greeson D. Cervical cancer prevention in the 21st century: cost is not the only issue. Am J Public Health. 2011;101(9):1549-55. doi:10.2105/ajph.2011.300204

11. Lee SM, Park JS, Norwitz ER, Koo JN, Oh IH, Park JW, et al. Risk of vertical transmission of human papillomavirus throughout pregnancy: a prospective study. PLoS One. 2013;8(6):e66368. doi:10.1371/journal.pone.0066368

12. Tuladhar E, Terpstra P, Koopmans M, Duizer E. Virucidal efficacy of hydrogen peroxide vapour disinfection. J Hosp Infect. 2012;80(2):110-5. doi:10.1016/j.jhin.2011.10.012

13. Meyers J, Ryndock E, Conway MJ, Meyers C, Robison R. Susceptibility of high-risk human papillomavirus type 16 to clinical disinfectants. J Antimicrob Chemother. 2014;69(6):1546-50. doi:10.1093/jac/dku006

14. Stern PL, van der Burg SH, Hampson IN, Broker TR, Fiander A, Lacey CJ, et al. Therapy of human papillomavirus-related disease. Vaccine. 2012;30 $\begin{array}{llll}\text { Suppl } & 5 & (0 & 5): F 71-F 82 .\end{array}$ doi:10.1016/j.vaccine.2012.05.091

15. Fradet-Turcotte A, Archambault J. Recent advances in the search for antiviral agents against human papillomaviruses. Antivir Ther. 2007;12(4):431-51.

16. Miller RL, Gerster JF, Owens ML, Slade HB, Tomai MA. Imiquimod applied topically: a novel immune response modifier and new class of drug. Int J Immunopharmacol. 1999;21(1):1-14. doi:10.1016/s0192-0561(98)00068-x

17. Lipke MM. An armamentarium of wart treatments. Clin Med Res. 2006;4(4):273-93. doi:10.3121/cmr.4.4.273

18. Yanofsky VR, Patel RV, Goldenberg G. Genital warts: a comprehensive review. J Clin Aesthet Dermatol. 2012;5(6):25-36.

19. Das S. Human Papillomavirus Infection: Management and Treatment. London (UK): IntechOpen; 2020. doi:10.5772/intechopen.92397

20. Mutombo AB, Tozin R, Kanyiki H, Geertruyden JPV, Jacquemyn Y. Impact of antiviral AV2 in the topical treatment of HPV-associated lesions of the cervix: Results of a phase III randomized placebo- controlled trial. Contemp Clin Trials Commun. 2019;15:100377. doi:10.1016/j.conctc.2019.100377

21. Dunjic M, Stanisic S, Krstic D, Stanisic M, Ignjatic ZJ, Dunjic M. Integrative approach to diagnosis of genital human papillomaviruses (HPV) infection of female. Acupunct Electrother Res. 2014;39(34):229-39. doi:10.3727/036012914x14109544776051

22. Zanier K, Sidi AM, Boulade-Ladame C, Rybin V, Chappelle A, Atkinson A, et al. Solution structure analysis of the HPV16 E6 oncoprotein reveals a self-association mechanism required for E6mediated degradation of p53. Structure. 2012;20(4):604-17. doi:10.1016/j.str.2012.02.001

23. Facciuto F, Valdano MB, Marziali F, Massimi P, Banks L, Cavatorta AL, et al. Human papillomavirus (HPV)-18 E6 oncoprotein interferes with the epithelial cell polarity Par3 protein. Mol Oncol. 2014;8(3):533-43. doi:10.1016/j.molonc.2014.01.002

24. Saikia S, Bordoloi M. Molecular Docking: Challenges, Advances and its Use in Drug Discovery Perspective. Curr Drug Targets. 2019;20(5):501-21. doi:10.2174/1389450119666181022153016

25. Du X, Li Y, Xia YL, Ai SM, Liang J, Sang P, et al. Insights into Protein-Ligand Interactions: Mechanisms, Models, and Methods. Int J Mol Sci. 2016;17(2):144. doi:10.3390/ijms17020144

26. Robinson PK. Enzymes: principles and biotechnological applications. Essays Biochem. 2015;59:1-41. doi:10.1042/bse0590001

27. Ferreira LG, Dos Santos RN, Oliva G, Andricopulo AD. Molecular docking and structure-based drug design strategies. Molecules. 2015;20(7):13384-421. doi:10.3390/molecules200713384

28. Kolb P, Irwin JJ. Docking screens: right for the right reasons? Curr Top Med Chem. 2009;9(9):755-70. doi:10.2174/156802609789207091

29. Meng XY, Zhang HX, Mezei M, Cui M. Molecular Docking: A powerful approach for structure-based drug discovery. Curr Comput Aided Drug Des. 2011;7(2):146-57. doi:10.2174/157340911795677602

30. Pinzi L, Rastelli G. Molecular Docking: Shifting Paradigms in Drug Discovery. Int J Mol Sci. 2019;20(18):4331. doi:10.3390/ijms20184331 
31. Park MS, Gao C, Stern HA. Estimating binding affinities by docking/scoring methods using variable protonation states. Proteins. 2011;79(1):304-14. doi:10.1002/ prot.22883

32. Wootten D, Reynolds CA, Smith KJ, Mobarec JC, Furness SGB, Miller LJ, et al. Key interactions by conserved polar amino acids located at the transmembrane helical boundaries in Class B GPCRs modulate activation, effector specificity and biased signalling in the glucagon-like peptide1 receptor. Biochem Pharmacol. 2016;118:68-87. doi:10.1016/j.bcp.2016.08.015

33. Dhifi W, Bellili S, Jazi S, Bahloul N, Mnif W. Essential Oils' Chemical Characterization and Investigation of Some Biological Activities: A Critical Review. Medicines. 2016;3(4):25. doi:10.3390/medicines3040025 